\title{
Bullying Victimization: Investigating the Unique Contribution of Homophobic Bias on Adolescent Non-suicidal Self-injury and the Buffering Role of School Support
}

\author{
Concetta Esposito ${ }^{1}$ (1) $\cdot$ Gaetana Affuso $^{2} \cdot$ Anna Lisa Amodeo $^{1} \cdot$ Mirella Dragone $^{1} \cdot$ Dario Bacchini $^{1}$
}

Accepted: 9 January 2021 / Published online: 6 March 2021

(c) The Author(s) 2021

\begin{abstract}
Research on bullying victimization has expanded to specific forms of harassment based on discriminatory bias, which involve aggressive behavior targeting an individual's identity characteristics, such as sexual orientation and/or gender expression. Recent studies have documented elevated health risks associated with victimization based on homophobic bias, above and beyond general victimization. The aim of the current study was to test the unique contribution of homophobic victimization on adolescent non-suicidal self-injury (NSSI) and to analyze the buffering role of teachers and classmates support. Participants were 770 adolescents $(55.5 \%$ females; $M$ age $=15.35, S D=1.62)$ enrolled in Italian public schools in grade nine $(N=483)$ and $12(N=287)$. All measures were collected during Spring 2016 using self-reported questionnaires. Zero-inflated Poisson regression analyses suggested that homophobic victimization had a unique contribution on NSSI frequency of engagement once initiated, but not on the probability of engaging in NSSI at least once. High classmates support was negatively associated with adolescents' engagement in NSSI. Furthermore, higher levels of classmates support were associated with a lower NSSI frequency only for youth who reported low levels of homophobic victimization. In contrast, the association between classmates support and NSSI frequency was nonsignificant when youth reported high levels of homophobic victimization. No significant effects were found for teachers support. Overall, our findings underscore the need to address the serious concern of homophobic victimization within schools and the importance of promoting healthy and positive identity development in adolescence.
\end{abstract}

Keywords Non-suicidal self-injury $\cdot$ Homophobic victimization $\cdot$ Bullying victimization $\cdot$ School support $\cdot$ Teachers support · Classmates support · Adolescence

\section{Introduction}

Bullying victimization is an ongoing public health concern worldwide. It is generally defined as a repeated exposure to negative actions from one or more peers, aimed at causing harm to the victim and operating within an imbalance of power between perpetrator(s) and victim(s) (Olweus, 2010). Bullying victimization can occur through a variety of direct and indirect behaviors, ranging from verbal insults to social

Concetta Esposito

concetta.esposito3@unina.it

1 Department of Humanistic Studies, University of Naples "Federico II", Via Porta di Massa 1, 80133 Napoli, Italy

2 Department of Psychology, University of Campania "Luigi Vanvitelli", Caserta, Italy exclusion, threats, and physical aggression. Both these forms of peer victimization have been found to be associated with serious mental and physical health consequences in both children and adolescents (Gini et al., 2014; Holt et al., 2015; Moore et al., 2017; Ttofi et al., 2011).

Recently, research on bullying victimization has expanded to specific forms of harassment based on discriminatory bias (Russell et al., 2012), which involves aggressive behavior targeting an individual's identity characteristics such as race/ ethnicity, sexual orientation and gender expression, religion, or disability. This kind of school harassment, also referred to as identity-based bullying (Bradshaw \& Johnson, 2011; Poteat et al., 2011; Price et al., 2019), is common during the middle and high school years (Kosciw et al., 2018), when adolescents are typically engaged in the process of identity exploration and formation (Smetana et al., 2006). Indeed, perceptions of discrimination based on identity 
characteristics are strictly related to the development of individuals' awareness of their identity (Garnett et al., 2014).

Given the relevance that identity concerns assume during adolescence, victimization based on identity characteristics may have greater health implications than general victimization. In this study, we focus on experiences of bullying victimization based on homophobic prejudice, consisting of negative beliefs and behaviors targeting those people who do not conform to traditional heterosexual gender norms (Bacchini et al., 2020; Meyer, 2008). Homophobic victimization mainly involves sexual diverse youth (e.g., gay, lesbian, and bisexual youth) because of their sexual orientation that is perceived as non-conforming to traditional heterosexual norms. As heterosexuality is deeply rooted in the idea that males and females have distinct characteristics and roles that in turn elicits rigid behavioral gender-based expectations (Butler, 2011), homophobic victimization often extends also to gender diverse youth (e.g., transgender or questioning youth) because of their gender non-conforming identity (E.J. Meyer, 2008). In addition, homophobic victimization may also concern heterosexual and cisgender youth who are perceived as deviating from traditional masculine/feminine gender role expectations (Poteat et al., 2013; Tucker, Ewing, et al., 2016; Tucker, Wingate, et al., 2016).

The prevalence of homophobic victimization is illustrated in several studies from the US context, whereas the investigation of prevalence rates in Europe is still limited. The results from the US National School Climate Survey (GLSEN; Kosciw et al. 2018) indicated that, in 2017, 82\% and $37 \%$ of sexual minority students across the nation experienced verbal harassment or physical attacks, respectively, based on their sexual orientation and/or gender expression. In the same year, a report published by Stonewall (Bradlow et al., 2017) showed that nearly half of sexual minority UK students were bullied because of their sexual orientation and/ or gender identity, and $86 \%$ regularly heard phrases such as "that's so gay" or "you're so gay" in school, with two in three $(66 \%)$ hearing such comments frequently or often.

Previous studies have highlighted the detrimental effects of homophobic victimization on youth mental health, both in minority and in non-minority groups (e.g., Espelage et al. 2008). Specifically, experiences of homophobic victimization are associated with anxiety, depression, and suicidality (Birkett et al., 2009; Poteat \& Espelage, 2007; Rinehart et al., 2020), substance abuse, and psychological distress (D’Augelli et al. 2002; Tucker, Ewing, et al., 2016; Tucker, Wingate, et al., 2016), with positive peer relationships and school climate buffering these effects (Espelage et al., 2019). Overall, research examining the association of homophobic victimization with self-injurious behavior is limited to suicidal behavior, underscoring the importance of considering the engagement in self-injurious behavior without suicidal intent as a potential outcome linked to experiences of homophobic victimization (Taliaferro \& Muehlenkamp, 2017). The present study aimed to address this gap in the literature by investigating the effects of homophobic victimization on the probability of engaging in non-suicidal self-injury (NSSI) behavior, as well as on the frequency of engaging in NSSI once initiated. We analyzed these associations accounting for the effects of general victimization (i.e., non-bias based), thus examining whether homophobic victimization had a significant effect on NSSI over and above traditional forms of victimization. Furthermore, we investigated the potential buffering role of teachers and classmates support.

\section{Victimization Based on Homophobic Bias}

Despite their strong overlapping, homophobic and general victimization represent two distinct forms of peer victimization. Both can manifest through direct (such as physical assaults, verbal insults, teasing, intimidation) and indirect modalities (such as spreading rumors or exclusion from group activities), or using electronic devices (Hong \& Garbarino, 2012). However, they differ from each other due to the fact that homophobic attacks convey a specific threat to one's sexual identity, emphasizing the marginalized social position of sexual minority youth and those who are perceived to not conform to traditional gender roles (Tucker, Ewing, et al., 2016; Tucker, Wingate, et al., 2016). In line with these arguments, homophobic victimization has been found to increase the risk of several negative outcomes compared to general victimization. In their study testing the effects of general and homophobic victimization on a variety of psychological and academic outcomes, Poteat et al. (2011) found that homophobic victimization had a unique contribution on adolescents' suicidal ideation, over and above general victimization. This result has been interpreted within the minority stress framework (Meyer, 2003), according to which individuals from minority groups experience unique, chronic, and institutionalized stressors that put them at higher risk of mental health problems.

Minority stressors have been conceptualized in terms of distal and proximal processes (Meyer, 2003): Distal processes refer to objective stressors independent of the individual (e.g., prejudice events), whereas proximal processes refer to stressors that depend on the individual, as they are linked to the individual's feelings, thoughts, and actions, as well as to one's subjective perceptions and evaluations (e.g., internalized homophobia). Based on this perspective, homophobic victimization represents the most prominent distal stressor faced by sexual minority youth, emphasizing the individual perception of the self as belonging to a stigmatized and devalued group. 
Notably, homophobic victimization has been associated with negative psychological outcomes in heterosexual youth as well (Poteat et al., 2014), perhaps due to the marginalized minority identity that others have conferred on them (Tucker, Ewing, et al., 2016; Tucker, Wingate, et al., 2016). The findings from a short-term longitudinal study (Poteat et al., 2014) provide empirical support to the minority stress model applied to heterosexual adolescents, showing that homophobic victimization positively predicted anxiety and depression, over and above levels attributable to general victimization. When looking at longitudinal associations, the authors found that males who experienced greater homophobic victimization than others at the beginning of the school year (baseline point) also experienced greater homophobic victimization than others at the end of the school year, and this association did not hold for females. Furthermore, only in male participants, homophobic victimization predicted anxiety and depression over time. These results were consistent with the authors' expectations based on masculinity theories, arguing that males can interpret homophobic victimization as a key challenge to their heterosexuality and their masculinity, especially during adolescence, when gender roles are explored and formed. Consistent with this finding, other studies have found that adolescent males who were targeted with homophobic epithets by peers reported greater levels of anxiety and depressive symptoms than boys who were bullied for other reasons (Swearer et al., 2008), or regardless of being bullied without connection to bias (Slaatten et al., 2015).

Taken together, these results suggest that homophobic victimization has a unique contribution to the development of negative outcomes in adolescence, increasing the risk of internalizing symptoms over and above general victimization. Noteworthy, not only sexual minority youth are at risk of negative developmental outcomes, but heterosexuals as well.

\section{NSSI and Homophobic Victimization}

NSSI refers to the direct and deliberate destruction of one's body tissue without conscious suicidal intent and for purposes that are not culturally accepted (Nock, 2009). NSSI is a serious concern among adolescents, with prevalence rates estimated at around 14-24\% (Swannell et al., 2014), also in non-clinical samples (Esposito et al., 2019). It is frequently associated with stressful life events and several psychopathological conditions, such as post-traumatic stress disorder, depression or anxiety (Cipriano et al., 2017).

A wide variety of functions for NSSI have been identified (Klonsky, 2007; Taylor et al., 2018), distinguishable into intra-personal (e.g., NSSI that serves to manage one's negative emotions) and inter-personal functions (e.g., NSSI that serves to facilitate escape from social situations or to elicit attention and promote help-seeking behavior). Overall, it is suggested that people use NSSI as a maladaptive strategy to cope with their affective and social experience arising from stressful events, because of intra- or interpersonal vulnerabilities that predispose them to perceive such events as particularly overwhelming and difficult to handle (Nock, 2009).

Peer victimization has been found among the main predictors of NSSI in adolescence (Moore et al., 2017; van Geel et al., 2015), with bullying victims being two times more likely to engage in NSSI with respect to children uninvolved in school bullying (van Geel et al., 2015). No study, to our knowledge, has examined whether victimization based on homophobic bias increases the risk of engaging in NSSI, in addition to general victimization. Some studies taking into account both forms of peer aggression have examined suicidality as an outcome, providing support for the unique contribution of homophobic bias (Poteat et al., 2011). However, there are at least two specificities of engaging in NSSI that make this behavior deserving a specific examination. First, adolescents who engage in NSSI do not intend to end their own life; second, NSSI involves methods that are different from suicide-related behavior (for example, cutting and burning, rather than behaviors involving firearms, hanging, or self-poisoning).

There is some evidence suggesting that both suicidal thoughts and behaviors and NSSI are more common among sexual minorities than within the heterosexual community (Liu \& Mustanski, 2012; Marshal et al., 2011). Sexual minority adolescents and college students are two to seven times more likely to attempt suicide (Haas et al., 2010) and three to five times more likely to engage in NSSI (Liu \& Mustanski, 2012; Reisner et al., 2014). These results were confirmed in a recent meta-analysis comparing the risk for NSSI in sexual minority and heterosexual persons (Batejan et al., 2015). More specifically, the authors found that sexual minorities were at higher risk than heterosexual persons, also suggesting that younger age was an additional stressor that deserves further investigation. In the study by Garnett et al. (2014), high school students who reported to have been discriminated or bullied because of their sexual orientation had higher odds of engaging in deliberate self-harm compared to those who reported any discrimination experience. In the study by Taliaferro and Muehlenkamp (2017), high school sexual minority students were significantly more likely to report repetitive NSSI than heterosexual youth did. Finally, using a sample of sexual minority college students, Muehlenkamp et al. (Muehlenkamp et al., 2015) found that repeated experiences of discrimination related to sexual orientation increased the risk of engaging in NSSI.

Using the minority stress model as an interpretative framework, victimization experiences based on homophobic bias represent potentially inter- and intra-personal stressors 
that can be perceived as particularly overwhelming and difficult to handle, thus increasing the likelihood to engage in NSSI behaviors. At interpersonal level,

societal (e.g., homo/bi/transphobic prejudices and discrimination that are held in society, sometimes materializing in microaggressions) and victimization experiences (including being physically hurt, verbally teased, or subjected to anti-gay jokes) directly attack the individual's identity, emphasizing one's marginalized position. Similarly, intrapersonal stressors that arise from the internalization of negative messages may lead sexual minorities to believe that they are not valued and that their identities are wrong or immoral. However, the literature examining whether being a victim of homophobic bullying has a greater effect on NSSI engagement, besides the effects of being victimized for other reasons, is still limited.

\section{Teachers and Classmates Support as Protective Factors}

Most research on NSSI in adolescence has focused on risk factors (Valencia-Agudo et al., 2018). Much less is known about factors that could buffer the impact of biasbased victimization (Mulvey et al., 2018) or minimize the risk of engaging in NSSI in adolescence (Klemera et al., 2017; Valencia-Agudo et al., 2018). Prior studies have highlighted the importance of social support in managing identity-related stress (Denny et al., 2016; Espelage et al., 2008; Fedewa \& Ahn, 2011), also with respect to suiciderelated behaviors and NSSI (Busby et al., 2020; Hatchel et al., 2019).

Overall, perceived social support reflects the feeling that one is loved and valued and can rely on others for support when faced with stressful situations (Cobb, 1976; Lakey $\&$ Cohen, 2000). Based on the stress-buffering hypothesis (Cohen \& Wills, 1985), perceiving social support may reduce the perception of harm posed by a specific situation, thus preventing the stress appraisal response. On the other hand, it can provide individuals with the ability to manage and cope with stressful situations (Cohen, 2004). Among those commonly observed, such as the support provided by the family (Claes et al., 2015; Hershberger \& D'Augelli, 1995; Jiang et al., 2016), school-based sources of support, such as teachers and classmates, have received increasing attention (Kidger et al., 2015; Madjar et al., 2017; RossReed et al., 2019). When peer victimization occurs in the school context, indeed, teachers and classmates are among the first people who can provide support and assistance to the victims. Perceptions of teachers as unfair and a low sense of belonging among peers have been found to significantly predict self-harm behaviors longitudinally (Kidger et al., 2015). Furthermore, in a multilevel study on teacher and peer support carried out by Madjar et al. (2017), the quality of peer relationships at the classroom level prevented high school students from engaging in NSSI, whereas students who engaged in NSSI reported a lack of support at the individual level.

While several studies support the moderating effect of teachers and/or peers support in the relationship between traditional bullying victimization and self-injurious behaviors or suicide-related thoughts (Brunstein Klomek et al., 2016; Esposito et al., 2019), only limited research has been conducted taking into account victimization based on homophobic bias (Espelage et al., 2008; Taliaferro \& Muehlenkamp, 2017). Using a large sample of questioning and sexual minority students from Midwestern US public high schools, Espelage et al. (2008) found that students reporting the highest suicidal feelings were those who experienced the highest frequency of homophobic teasing and perceived the lowest levels of school support. However, when analyzing the moderating role of school support sources with respect to the specific outcome of adolescent engagement in NSSI, Taliaferro and Muehlenkamp (2017) found that perceptions of caring from teachers and friends did not buffer the impact of homophobic bias on NSSI in a sample of sexual minority youth. Collectively, these findings highlight the need to bolster our knowledge about the role of school-based sources of support in the relationship linking victimization based on homophobic bias to NSSI among adolescents.

\section{Homophobic Victimization in Italian High Schools}

Traditional gender stereotypes are deeply rooted within the Italian culture, shaping socialization practices and mechanisms that contribute to biased expectations that certain attributes and behaviors are associated with men and certain others with women. The construction of this stereotypical gender view has been highly influenced by the relatively strong power of the Catholic Church in shaping Italians' beliefs and attitudes toward gender roles, and, more in general, by the Mediterranean and Western Europe traditions (Tager \& Good, 2005). As a consequence, discriminations based on sexual and gender identity are quite common throughout the country. A recent Eurobarometer survey in the European Union (Discrimination in the European Union. Special Eurobarometer 493, 2019) showed that the Italian context is characterized by high levels of negative attitudes toward sexual and gender minorities. This evidence has been supported by a recent transnational study (Passani \& Debicki, 2016), reporting that Italian high school students consider the society in which they live as discriminatory against homosexuality, and their schools as not welcoming environments for sexual and gender minorities. 
Data about the prevalence of homophobic victimization in Italian schools are very few (Ioverno et al., 2016; Prati et al., 2011). In the study by Prati et al. (2011), homophobic behaviors were reported to be widespread in the schools. Of the total sample, about half reported to have "often" or "always" heard homophobic epithets directed to sexual and gender minority students. Similarly, about half of the sample reported to have red homophobic insults on the school walls, whereas about $20 \%$ have seldom seen a student isolated or assaulted because she/he was or seemed to be homosexual. Furthermore, differently from other several European countries (e.g., Ireland, the Netherlands, Belgium, the UK), where schools are provided with specific national guidelines and trainings to deal with homophobic bullying, Italian schools miss any kind of institutional support to address this issue, and topics related to sexual and gender identity are quite invisible within schools (Ioverno et al., 2016).

\section{Purpose of the Current Study}

This study sought to extend the previous literature by examining the association of victimization based on homophobic bias with adolescent engagement in NSSI behavior, accounting for the effect of general victimization. Using zero-inflated Poisson (ZIP) regression analyses, we considered as outcomes both the probability of engaging in NSSI at least once and the frequency of NSSI behavior once initiated. Efforts to highlight possible differences in the developmental pathways toward NSSI onset versus recurrence have been highly recommended in the literature (Gonzalez-blanks et al., 2020). Prior work, for example, has suggested that social and peer factors significantly affect NSSI initiation, whereas intrapersonal factors tend to be more strongly associated with NSSI recurrence (Muehlenkamp et al., 2013).

Further, we investigated whether teachers and classmates support prevents victimized adolescents from engaging in NSSI, and/or reduce the frequency of NSSI engagement once initiated. Then, we tested whether these interaction effects were conditional on school grade. We hypothesized that (i) homophobic victimization had an independent contribution on NSSI, over and above general victimization (Hypothesis 1), (ii) both forms of school support (i.e., teachers and classmates support) buffered the effect of homophobic victimization on NSSI (Hypothesis 2), and that (iii) school support had a stronger mitigating effect in grade 12 compared to grade nine. Indeed, differently from other school systems, the Italian high school is organized in a fiveyear school cycle. Students meet each other and their teachers in grade nine and stay in the same classes together for the entire school cycle (until grade 13). Thus, hypothesizing that relationships with classmates and teachers consolidate over time and that teachers' ability to create a positive classroom climate and foster positive student-student and student-teacher interactions may increase over the course of the school cycle, we expected that in grade 12 , they could play a stronger role in mitigating the effects of adolescents' stressful experiences. Finally, all the effects were controlled for adolescent gender.

\section{Method}

\section{Participants}

The original sample consisted of 786 adolescents from several public schools located in the metropolitan area of Naples, in the south of Italy. Data were collected by trained assistants in Spring 2016, during regular class hours. Parents' written informed consent and adolescents' assents were obtained prior to the administration of paper-andpencil questionnaires. Sixteen students were absent from school during the questionnaire administration. Thus, the final sample consisted of 770 high school students (55.5\% females). Participants were enrolled in grade nine $\left(\mathrm{n}=483 ; M_{\mathrm{age}}=14.21, S D=0.58\right)$ and grade $12(\mathrm{n}=287$; $\left.M_{\text {age }}=17.30, S D=0.68\right)$. The mean age of the total sample was $15.35(S D=1.62)$, ranging from 13 to 19 years. The socioeconomic distribution of participants' families reflected the Italian national statistics (Istituto Nazionale di Statistica, ISTAT 2016), with most of the fathers and mothers having obtained a high school degree $(58.9 \%$ of fathers and $50.5 \%$ of mothers) or a junior high school license $(24.4 \%$ of fathers and $26.7 \%$ of mothers).

\section{Measures}

\section{Traditional and Homophobic Victimization}

We used four items for each measure of traditional and homophobic victimization. A detailed definition of bullying victimization was included in the questionnaire, emphasizing the intention to harm the victim, the repetitive nature of episodes, and the imbalance in power between the victim and the perpetrator(s) as the three key elements of bullying. Items for general victimization were adapted from the classical bully-victim questionnaire (Olweus, 1996). We specifically asked participants to report the frequency with which they had been bullied during the last three months. Items were: (a) other students called me names; (b) other students spread rumors about me, (c) I have been physically attacked by other students; (d) other students excluded me from social activities (e.g., parties, sport activities, etc.). Items for homophobic victimization were worded such that they mirrored those for traditional victimization. Therefore, we 
asked participants to report how frequently, during the last three months, they were called names, targeted with negative rumors, physically harassed, or excluded by other students because of their being, or being considered as, gay, lesbian, or bisexual. Items were rated on a 5-point scale ranging from one (never) to five (several times a week). Cronbach's alphas indicated the adequate reliability of each scale, $\alpha s=0.83$ and 0.84 for traditional and homophobic victimization, respectively.

\section{Teachers and Classmates Support}

For measuring students' perceptions of teachers and classmates support, we used the Classroom Life Scale (Johnson et al., 1985), which captures both academic and personal dimensions of support. The questionnaire's items were translated from English into Italian by two native Italian speakers, experts in psychology and fluent in English, and then back-translated by a native English speaker to ensure its comparability to the English version. The questionnaire includes two teacher-related and two classmate-related subscales. Teacher-related subscales measure teacher academic (four items, such as "My teachers want me to do my best in schoolwork") and personal support (four items, such as "My teachers really care about me"). Classmate-related subscales refer to classmate academic (five items, such as "In this school, other students care about how much I learn") and personal support (four items, such as "In this school, other students like me the way I am"). Students were asked to respond to each item using a 5-point Likert-type scale from never (1) to always (5). Previous factorial analyses for this scale (Van Ryzin et al., 2009) revealed a two-factor rather than a four-factor solution, with the two factors corresponding to the combined teacher and peer-related items, without differentiating between academic and personal support. The factor structure of the questionnaire for the current study's sample was tested through confirmatory factor analysis (CFA). The results confirmed the adequate goodness of fit of the higher-order structure of the scale, with two second-order factors (i.e., teacher support and peer support), $\chi^{2}(114)=461.123, p<0.001 ; \mathrm{CFI}=0.96, \mathrm{RMSEA}=0.06$ $90 \%$ C.I. $[0.05,0.06]$, SRMR $=0.04$.
For the present study's purposes, teacher-related and classmate-related item scores were averaged to obtain a global measure of teacher and classmate support, respectively. Cronbach's alphas were 0.90 and 0.91 for teacher and classmate support, respectively.

\section{Non-Suicidal Self-Injury}

NSSI was assessed through a six-item scale (Giletta et al., 2012; Prinstein et al., 2008) measuring how frequently $(0=$ never $; 1=1-2$ times $; 2=3-5$ times $; 3=6-9$ times; $4=10$ or more times), during the last six months, adolescents intentionally engaged in several types of self-injurious behaviors without suicidal intentions (such as cutting, burning, or hitting oneself). This measure has been previously administered to adolescent samples, including Italian adolescents (Giletta et al., 2012), and has shown good reliability and convergent validity, correlating highly with a widely used single-item measure of NSSI (i.e., "How often have you intentionally harmed or hurt your body-for example by cutting or burning your skin-without intending to die?"; Prinstein et al., 2008). Percentages of adolescents in the study's sample who engaged in each NSSI behavior are shown in Table 1 . The most commonly reported type of NSSI was cutting or carving skin, followed by scraping skin to draw blood. As we were interested in NSSI probability of engagement and frequency, regardless of the specific behaviors, we used a composite score of NSSI, obtained by summing the frequency rating for each item, in line with prior research (e.g., Giletta et al. 2012; Prinstein et al. 2008). In the current sample, Cronbach's alpha was 0.86 , indicating a good scale's reliability.

\section{Statistical Analysis}

To examine the associations of traditional and homophobic victimization with the probability of engaging in NSSI, as well as the frequency of NSSI once initiated, we conducted zero-inflated Poisson (ZIP) regression analyses in Mplus 8 (Muthén \& Muthén, 2017), controlling for the non-independence of observations. This approach has been demonstrated to be particularly suitable for analyzing
Table 1 Percentages of adolescents who engaged in NSSI behaviors

\begin{tabular}{llllll}
\hline & Never & $1-2$ times & $3-5$ times & $6-9$ times & 10 or more \\
\hline Cutting or carving skin & 89.5 & 6.1 & 1.9 & 0.8 & 1.7 \\
Self-biting & 94.7 & 2.9 & 1.6 & 0.5 & 0.4 \\
Inserting objects under skin or nails & 94.7 & 2.1 & 1.8 & 0.9 & 0.5 \\
Burning skin & 96 & 2.2 & 0.6 & 0.5 & 0.6 \\
Scraping skin to draw blood & 92.2 & 3 & 2.1 & 1.2 & 1.6 \\
Self-hitting & 95.3 & 1.7 & 1.9 & 0.4 & 0.6 \\
\hline
\end{tabular}


highly-skewed variables with an overabundance of zeros (Lambert, 1992), such as the frequency of NSSI in community samples (Gonzalez-blanks et al., 2020). Descriptive statistics to check for the presence of overdispersion and zero-inflation and comparisons with competing models (i.e., negative binomial and zero-inflated negative binomial models) are reported in supplementary materials. ZIP models examine two processes simultaneously: The probability of occurrence of a specific behavior (i.e., whether or not an individual engages in a behavior) and how often this behavior is expressed once initiated. We run three ZIP regression models. First, we analyzed the main effects of traditional and homophobic victimization, teachers and classmates support, controlling for adolescent age and gender. Then, we run two separate ZIP regression models for estimating the interactive effects of teachers and classmates support, respectively. More specifically, we first tested two- and three-way interaction effects, analyzing the moderating role of teachers and classmates support in the relationship between homophobic victimization and NSSI probability of engagement and frequency, and examining whether such interactions were conditional on school grade. In the first model, we added into the regression model the two-way interactions between homophobic victimization and classmates support, homophobic victimization and school grade, school grade and classmates support, and the three-way interaction term between homophobic victimization, classmates support and school grade. The same procedure was applied when analyzing the moderation of teachers support. Significant conditional effects were probed by using the pick-a-point approach, estimating the effect of the predictor at \pm 1 S.D. values of the moderator (Aiken et al., 2012).

\section{Results}

\section{Descriptive Statistics and Correlations}

Table 2 reports means, standard deviations and bivariate correlations among the study's variables. As can be observed, both homophobic and general victimization were positively associated with NSSI engagement and NSSI frequency. Homophobic victimization did not correlate with classmates and teachers support, whereas higher levels of general victimization were associated with lower perceptions of classmates and teachers support, and vice versa. Perceptions of classmates support positively correlated with perceptions of teachers support. Furthermore, classmates support was significantly and negatively linked to both NSSI engagement and frequency, whereas teachers support only negatively correlated with NSSI frequency. With respect to school grade, younger adolescents reported higher levels of teacher support and NSSI. Adolescent sex was only associated with general victimization, with males reporting higher levels.

\section{Prevalence of Victimization and NSSI Engagement}

Overall, participants who reported to have being bullied at least one or two times in the last three months were $36 \%$ of the total sample, whereas the prevalence rate of homophobic victimization was around $7.3 \%$. The Chi-square test revealed no significant differences in rates of homophobic victimization across school grade groups, $\chi^{2}(1)=0.11, p=0.75$, and gender, $\chi^{2}(1)=0.09, p=0.77$. Adolescents who selfreported to engage in NSSI at least once were 126 (16.3\% of the total sample). Of those who engaged in NSSI, 74.1\% were enrolled in grade nine, $\chi^{2}(1)=5.30, p<0.05$. No differences were found on the basis of adolescent gender, $\chi^{2}$ (1) $=0.04, p=0.84$.

Table 2 Descriptive statistics and correlations among study variables

\begin{tabular}{|c|c|c|c|c|c|c|c|c|c|c|}
\hline & 1 & 2 & 3 & 4 & 5 & 6 & 7 & 8 & Mean & $S D$ \\
\hline 1. School grade (9th vs. 12th) & 1 & & & & & & & & - & - \\
\hline 2. Sex (Male vs. Female) & $0.17 * * *$ & 1 & & & & & & & - & - \\
\hline 3. Homophobic victimization & 0.01 & -0.06 & 1 & & & & & & 1.08 & 0.41 \\
\hline 4. Traditional victimization & -0.02 & $-0.10 * *$ & $0.41 * * *$ & 1 & & & & & 1.25 & 0.50 \\
\hline 5. Classmates support & 0.00 & 0.06 & -0.01 & $-0.18 * * *$ & 1 & & & & 3.04 & 0.88 \\
\hline 6. Teachers support & $-0.13 * * *$ & 0.04 & -0.02 & $-0.13 * * *$ & $0.48 * * *$ & 1 & & & 3.42 & 0.84 \\
\hline 7. Engagement in NSSI (no/yes) & $-0.08^{*}$ & 0.01 & $0.15^{* * *}$ & $0.17 * * *$ & $-0.11 * * *$ & -0.06 & 1 & & - & - \\
\hline 8. Frequency of NSSI (mean score) & $-0.08 *$ & -0.02 & $0.28 * * *$ & $0.17 * * *$ & $-0.08^{*}$ & $-0.07 *$ & $0.74 * * *$ & 1 & 1.12 & 0.43 \\
\hline
\end{tabular}

Note: $S D$, standard deviation

${ }^{*} p<.05, * * p<.01, * * * p<.001$ 


\section{Main Effects of Homophobic and General Victimization, Teachers and Classmates Support}

Results from the ZIP regression model analyzing the main effects of victimization and school support are reported in Table 3. As can be observed, the probability of engagement in NSSI was predicted by general victimization, but not by victimization based on homophobic bias. Furthermore, only classmates support decreased the likelihood to engage in NSSI. With respect to NSSI frequency of engagement, we found a significant and positive effect of homophobic victimization, independent of general victimization, such that the frequency of NSSI episodes increased by 58\% with each one-unit increase in homophobic victimization. Among control variables, adolescent gender had no effect on both NSSI outcomes, whereas being in grade nine was associated with a greater probability of engaging in NSSI at least once.

\section{Moderation Analyses}

We analyzed the moderating role of teachers and classmates support, potentially conditional on school grade. As reported in Table 4, no significant interaction effects were found for teachers support. When analyzing the moderation of classmates support, we found that classmates support moderated the relationship between homophobic victimization and NSSI frequency (Fig. 1). The analysis of simple slopes revealed that classmates support had an effect on NSSI frequency only when homophobic victimization was low, $b=-0.64, p<0.05$, but not when it was high, $b=0.03$, $p=0.82$. School grade did not moderate these effects (all $p \mathrm{~s}>0.05)$.

\section{Discussion}

In this study, we investigated whether adolescents who reported being victims of homophobic bullying were more likely to engage in NSSI behavior, as well as to increase the frequency of engaging in NSSI once initiated. These
Table 3 Summary of the zeroinflated Poisson regression analyses. Main effects on the probability of engaging in NSSI and frequency of NSSI once initiated

\begin{tabular}{|c|c|c|c|c|c|c|}
\hline \multirow{2}{*}{$\begin{array}{l}\text { Predictors } \\
\text { Main effects }\end{array}$} & \multicolumn{2}{|c|}{ Probability of NSSI } & \multicolumn{4}{|c|}{ Frequency of NSSI } \\
\hline & $B$ & S.E & $B$ & S.E & $I R R$ & $95 \%$ C.I \\
\hline School grade (Grade 12) & $-0.57 *$ & 0.21 & -0.37 & 0.23 & 0.69 & {$[0.37 ; 1.01]$} \\
\hline Gender (female) & 0.17 & 0.22 & -0.06 & 0.23 & 0.94 & {$[0.52 ; 1.36]$} \\
\hline Homophobic victimization & 0.27 & 0.22 & $0.45 * * *$ & 0.12 & 1.58 & {$[1.32 ; 1.83]$} \\
\hline Traditional victimization & $0.47 * *$ & 0.17 & 0.03 & 0.12 & 0.98 & {$[0.79 ; 1.17]$} \\
\hline Classmates support & $-0.27 *$ & 0.15 & 0.03 & 0.14 & 1.03 & {$[0.74 ; 1.32]$} \\
\hline Teachers support & -0.12 & 0.16 & -0.04 & 0.13 & 0.97 & {$[0.73 ; 1.20]$} \\
\hline
\end{tabular}

Note. Bs refer to unstandardized coefficients. IRR, incident rate ratio. Probability of NSSI refers to the probability of being eligible for a nonzero response

${ }^{* * * *} p<.001, * * p<.01, * p<.05$

\begin{tabular}{|c|c|c|c|c|}
\hline & \multicolumn{2}{|c|}{$\begin{array}{l}\text { Probability of } \\
\text { NSSI }\end{array}$} & \multicolumn{2}{|c|}{$\begin{array}{l}\text { Frequency of } \\
\text { NSSI }\end{array}$} \\
\hline & $B$ & S.E & $B$ & S.E \\
\hline Homophobic victimization $\mathrm{X}$ classmates support & 0.30 & 0.38 & $0.42 * *$ & 0.14 \\
\hline Homophobic victimization $\mathrm{X}$ school grade & 2.99 & 1.57 & 0.81 & 0.44 \\
\hline School grade $\mathrm{X}$ classmates support & 0.87 & 0.65 & -0.31 & 0.38 \\
\hline Homophobic victimization $X$ classmates support $X$ school grade & -0.78 & 0.46 & -0.13 & 0.12 \\
\hline Homophobic victimization $\mathrm{X}$ teachers support & -0.22 & 0.45 & 0.04 & 0.04 \\
\hline Homophobic victimization $\mathrm{X}$ school grade & 4.37 & 4.23 & 0.20 & 0.29 \\
\hline School grade $X$ teachers support & 1.11 & 1.20 & -0.77 & 0.46 \\
\hline Homophobic victimization $X$ teachers support $X$ school grade & -1.06 & 1.18 & 0.05 & 0.10 \\
\hline
\end{tabular}

Note. Unstandardized coefficients are reported. Probability of NSSI refers to the probability of being eligible for a nonzero response

${ }^{* *} p<.01$
Table 4 Results from the moderation analysis 


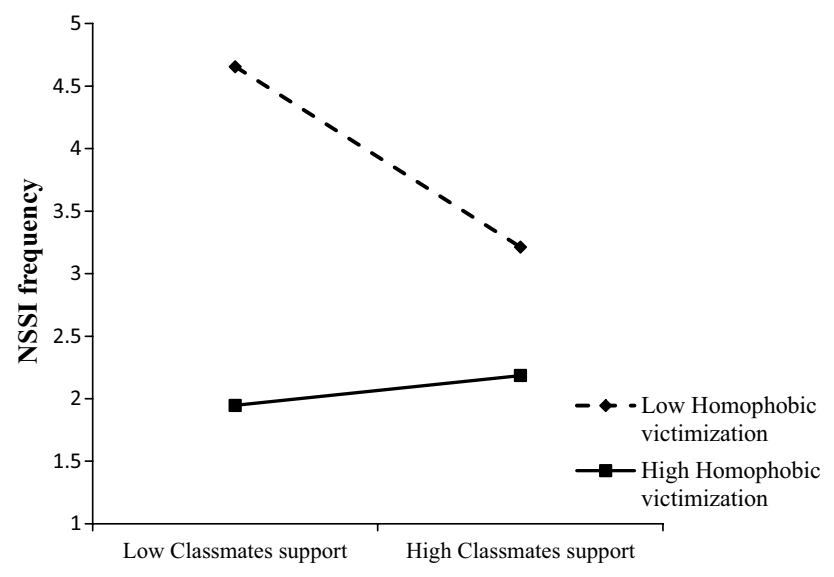

Fig. 1 Interaction between homophobic victimization and classmates support on NSSI frequency

associations were analyzed accounting for the effects of general victimization, thus investigating whether victimization based on homophobic bias had a significant effect on NSSI over and above non-biased-based victimization. Furthermore, we investigated the potential buffering role of teachers and classmates support and whether this effect was conditional on school grade.

We hypothesized that homophobic victimization had an independent contribution to NSSI, over and above general victimization (Hypothesis 1) and that teachers and classmates support prevented victimized adolescents because of homophobic bias to engage in NSSI (Hypothesis 2). The results partially confirmed our hypotheses, showing that being a victim of homophobic victimization only increased the frequency of adolescent engagement in NSSI once initiated, whereas general victimization was found to increase the likelihood of engagement in NSSI at least once. Perceiving high support by classmates, but not by teachers, was significantly associated with the engagement in NSSI at least once, specifically reducing the probability of NSSI occurrence. Also, we found a significant interaction effect between classmates support and NSSI frequency once initiated, indicating that perceived support by classmates was associated with NSSI frequency of engagement in NSSI only in adolescents who reported low homophobic victimization, with low levels of perceived support predicting higher NSSI frequency, and high levels of perceived support predicting a decrease of NSSI frequency. No effect was found for youth who reported high homophobic victimization. Furthermore, no buffering effect was found to be conditional on school grade.

This study involved a large sample of Italian high school adolescents, showing that slightly more than one in three students experienced bullying victimization during the last three months, whereas seven percent of the sample reported having been victimized on the basis of homophobic prejudice (about $23 \%$ of those who reported general victimization). The percentage of general victimization was similar to trends evidenced in USA (Pontes et al., 2018) and Europe (Barzilay et al., 2017). More complicated is the comparison of prevalence rates of homophobic victimization in Italy and other countries over the world, due to the use of different measures and time span. In a large sample of US adolescents, for instance, Russell et al. (2012) found that 15.5\% experienced homophobic physical and/or verbal harassment during the last 12 months. Higher levels of homophobic victimization have been recorded in a Spanish sample of 820 students (Rodriguez-Hidalgo and Hurtado-Mellado, 2019), with $23 \%$ of participants stating to have been victimized on the basis of actual or perceived differences in sexual orientation or gender identity during the last two months. Finally, in line with prevalence rates of NSSI reported in previous studies involving non-clinical samples, we found that about $16 \%$ of the total sample engaged in NSSI at least once in the last six months (Swannell et al., 2014). Interestingly, of those who reported having engaged in NSSI at least once, $74 \%$ were in grade nine. This result is consistent with general trends evidenced in the literature (Moran et al., 2012), supported by the hypothesis that difficulties in emotional control and risk-taking at younger age, perhaps related to underlying biological changes, represent crucial risk factors for NSSI.

\section{The Unique Contribution of Homophobic Victimization}

With respect to our first hypothesis about the independent contribution of homophobic victimization on NSSI outcomes, our results are consistent with previous studies finding that high school students who reported having been discriminated against or bullied because of their sexual orientation had a higher probability of engaging in self-harm behavior compared to those who reported any discrimination experience (Garnett et al., 2014; Muehlenkamp et al., 2015). In addition to providing further support to the existing limited literature, this study extends our knowledge by introducing two elements of novelty. First, we examined the effect of homophobic victimization controlling for general victimization, thus highlighting the specific contribution of homophobic bias, over and above non-biased-based forms of victimization. Second, using ZIP regression approach, we disentangled the effects of homophobic victimization on the probability of engagement in NSSI from the effect on the frequency of NSSI behavior once initiated. Consistent with previous research on the topic (e.g., Esposito et al. 2019), findings of the current study indicated that being victimized through non-biased forms was associated with a higher probability of engaging in NSSI at least once. Conversely, 
victimization based on homophobic bias increased the frequency of engagement in NSSI once initiated. This result would support the hypothesis that being a victim of homophobic bullying would have a different effect from general victimization in that it would be specifically associated with an increase of NSSI severity rather than with the onset of this set of self-injurious behaviors. This difference in NSSI severity might be explained by the fact that homophobic victimization could represent a specific threat to one's sexual identity, during a particular developmental period that emphasizes identity-related issues as key challenges in relation to identity exploration and formation (Smetana et al., 2006). Although not directly focused on NSSI, other previous studies have suggested that homophobic victimization has a unique contribution on a series of health-related outcomes, over and above general victimization (Poteat et al., 2011; Slaatten et al., 2015; Swearer et al., 2008), also without controlling for sexual orientation (Slaatten et al., 2015; Swearer et al., 2008). Overall, these results find their rational within the minority stress model (Meyer, 2003), according to which youth who are victimized on the basis of homophobic bias, regardless of their actual sexual orientation (Tucker, Ewing, et al., 2016; Tucker, Wingate, et al., 2016), experience unique stressors related to the identification with a minority identity, including the individual's perception of the self as belonging to a stigmatized and devalued group. Engaging in NSSI behaviors, in this case, might be a way to cope with painful emotions associated with feeling that one's self is inadequate, including sadness, anger, shame, and hatred toward the self (Breen et al., 2013).

\section{The Buffering Effect of Teachers and Classmates Support}

When analyzing the potential buffering effect of perceiving teachers and classmates support, we found that only perceiving classmates support prevented youth from engaging in NSSI at least once. This result is partially in line with our expectations and prior studies finding that both teachers support and the quality of peer relationships at school protected youth from the risk to engage in NSSI (Kidger et al., 2015; Madjar et al., 2017). However, these studies did not account for the effects of victimization, as our study did.

When examining the independent and conjoint contribution of victimization and social support, the previous literature has supported the hypothesis that peers play a key buffering role (Brunstein Klomek et al., 2016; Esposito et al., 2019). With respect to the interactive effects, our results showed only one significant interaction between homophobic victimization and classmates support on the frequency of engagement in NSSI once initiated. More specifically, we found that higher levels of classmates support were associated with decreased NSSI frequency only for youth who reported low levels of homophobic victimization, whereas the association between classmates support and NSSI frequency was nonsignificant when youth reported high levels of homophobic victimization. This effect could be interpreted as a "vulnerable-stable" process, as identified by Luthar et al. (2000) in the research on protective and resilience factors, where the general disadvantage of individuals with a particular attribute (homophobic victimization, in this case) remained stable despite changing levels of risk (classmates support, in this case). The different effects in victimized and non-victimized students could be interpreted in the sense that school-based sources of support are not able to buffer the effect of victimization experiences. However, it could also suggest that perceiving low levels of school support might be enough to limit the risk of repetitively engaging in NSSI behavior. A similar result was found in the study by Price et al. (2019). Examining the protective role of positive relationships with teachers in the association linking identity-based bullying and mental health outcomes, the authors found that positive teacher-student relationships had a mitigating effect on adolescent depression only for adolescents who did not report to be victims of identity-based bullying, whereas for those who were victims of identity-based bullying the association between relationships with teachers and depression was nonsignificant. Furthermore, these effects held in both subsamples of sexual minority and heterosexual youth. The study by Taliaferro and Muehlenkamp (2017) that examined the moderating role of perceived teacher and peer caring in the relationship between homophobic victimization and a series of psychological outcomes including NSSI showed no significant interaction effect (except for bisexual students), thus clearly suggesting that school-based factors might not be enough to buffer the effects of victimization that directly targets one's identity characteristics. Nevertheless, there is also another possible reason that might explain the absence of a buffering effect of school support for victims of bullying based on homophobic bias. In fact, there is evidence that homophobic bullying can negatively impact on schoolrelated factors, such as school climate and relationships with teachers and classmates (Espelage et al., 2019). Thus, being a victim of homophobic bullying might deteriorate relations with peers and school staff, such that the higher the rates of homophobic victimization, the lesser is the perception of connectedness with and support from significant others in the school context (Diaz et al., 2010; Poteat \& Espelage, 2007). This hypothesis would be consistent with the psychological mediation framework (Hatzenbuehler, 2009) that, extending the minority stress model (Meyer, 2003), highlights the role of social and interpersonal problems, such as negative relations with peers and parents, in mediating the relationship between minority stressors (e.g., peer 
victimization) and negative mental health outcomes. Such indirect association of peer victimization with suicidality through low perceptions of school belonging was supported in a recent study by Hatchel et al. (2019). Overall, negative perceptions of the school climate might be responsible for nonsignificant associations between school sources of support and negative outcomes in victimized students, whereas being not victimized would make youth sensitive to more or less supportive school environments. Overall, these findings indicate that examining the role of school sources of support in the relationship between homophobic victimization and NSSI deserves further attention in order to extend our understanding of how adolescents respond to stressful experiences related to their identity development.

\section{The Role of School Grade}

Finally, our findings support previous evidence highlighting that younger age increases the likelihood to engage in NSSI (Plener et al. 2015; Swannell et al. 2014), thus representing a significant factor risk that needs to be further investigated in research on self-injurious behaviors, together with specific aspects that characterize this specific developmental period. However, we did not find school grade moderating the hypothesized buffering effects of school support in the relationship between homophobic victimization and NSSI. Our hypothesis of a stronger mitigating effect in grade 12 was mainly based on the fact that we expected that relations with peers and teachers were stronger and more consolidated in the fourth year of Italian high school. Future studies might deepen the role of consolidated experiences within the school context.

\section{Limitations and Future Directions}

Our findings suggest that being victimized, regardless of homophobic content, is a risk factor for adolescent engagement in NSSI at least once. However, victimization based on homophobic bias contributes to increase the frequency of NSSI episodes once initiated. Furthermore, school-based sources of support seem insufficient to mitigate the impact of homophobic victimization on NSSI behavior. These results are promising, given the lack of studies disentangling the effects of homophobic and general victimization on NSSI probability of engagement and frequency. However, there are several limitations to be acknowledged. First, the crosssectional study's design and the use of two different time spans for measuring the occurrence of bullying victimization (last three months) and NSSI engagement (last six months) prevent us from inferring the likely causal nature of associations. However, this is a huge challenge when studying NSSI engagement in adolescence, given the high rates of discontinuation in NSSI behaviors (Plener et al., 2015). Also, we could not control for students' sexual orientation, given the current difficulty, at least in Italy, to obtain approval on school-based research to ask children about their sexual orientation. Thus, we could not know whether homophobic victimization was based on the perceived or actual sexual orientation of victims. One further limitation concerns the specific focus on victimization experiences based on homophobic bias, overlooking the importance of disentangling biases as stemming either from sexual or gender identity. Another limitation concerns the exclusive use of self-report measures that make our results at risk to be contaminated by shared variance associated with the use of a unique source of information. Furthermore, we did not consider several measures, such as anxiety/depression disorders, substance use, post-traumatic stress disorder, violence experiences, family support, and religious affiliation, that could play an important role in the relation between homophobic victimization and NSSI, and therefore need to be considered in further investigations.

Overall, findings of the current study support the need for further investigating how and whether NSSI behavior can be interpreted as a mechanism to cope with the stress associated with specific experiences of identity-based victimization, such as homophobic victimization, based on the evidence that intra- and interpersonal vulnerabilities that have been associated to NSSI behaviors well align with intra- and interpersonal stigma-related stressors associated with minority identities, actual or conferred by others. Further research helping to increase our understanding of the role of schoolbased sources of support for students who are victims of homophobic bullying also deserves attention, along with other support sources.

\section{Implications and Conclusions}

This research highlights the relevance that identity and personal attributes assume in the context of victimization experiences within high schools. Furthermore, it outlines the importance of considering severe manifestations of NSSI among the variety of mental health outcomes associated with school victimization based on homophobic bias, over and above general victimization. The presence of specific school anti-bullying and discrimination policies has been generally reported among the most effective actions to prevent and contrast homophobic victimization (Kosciw et al., 2018). Thus, schools' adoption of anti-bullying laws that protect students from attacks targeting their identity expression and from marginalization based on any perceived personal attribute is highly recommended for reducing victimization based on homophobic bias. 
Empirical evidence supports the hypothesis of bidirectional relationships between episodes of homophobic victimization and perceptions of school climate (Espelage et al., 2019), such that victimization episodes concur to a negative perception of school climate, but a positive perception of school climate can deter the occurrence of victimization episodes and eventually buffer their effect on mental health outcomes. Therefore, prevention and intervention efforts might reveal particularly beneficial if they also target the promotion of a positive school climate (Wang et al., 2013), where students feel safe and supported, and respectful, trusting, and caring relationships are encouraged throughout the school community. Specific actions might aim at increasing the awareness, within the school context, of the unique consequences that identity-based victimization has on youth who are targeted with, such that all members of the school community (teachers, staff, and peers) feel the responsibility of making schools safe, welcoming and respectful places where successfully achieving personal and academic goals, regardless of individual differences. Overall, there is limited evidence supporting the efficacy of bullying prevention programs (e.g., the Olweus Bullying Prevention Program) on enhancing general school climate perceptions. More specifically, significant improvements in students' satisfaction with school life and social relationships have been found in Norway (Olweus \& Limber, 2010). With respect to the US context, Bauer et al. (2007) found no significant effect of the program implementation on school climate perceptions. Only in a recent study by Limber and colleagues (Limber et al., 2018), an overall increase of behaviors that are more proximal to the intervention was documented (e.g., increasing of students' expressions of empathy with bullied peers, decreasing in their willingness to join in bullying, higher perceptions of teachers' willingness to address bullying incidents), suggesting, and not directly assessing, that the program had helped shift student attitudes to bullying and related behaviors to a more positive and inclusive school climate. However, it is important to note that neither of these interventions was designed to address identity- and stigmabased bullying specifically, or addressed stigma-related factors, such as issues of diversity, or how students in marginalized social positions perceive climate.

Given that schools are the main places where adolescents experience significant stressors, it is in the school setting that they also should find positive support and assistance when struggling with mental health problems. Several schoolbased prevention programs aiming at supporting adolescent coping with intense emotions and stress have been developed, but their effects on NSSI have been documented only to a limited extent (Baetens et al., 2020). For example, one of the most extensive programs in Europe, the Saving and Empowering Young Lives in Europe (SEYLE) program, involving 168 schools from ten countries, including Italy, only focused on the prevention of suicide in schools (Wasserman et al., 2015). In a recent pilot study examining the feasibility of a school-based mental health program for the prevention of NSSI in Belgium, the authors found that the addition of the NSSI-specific module to the program had direct benefits to some students with lived experience, such as increased help-seeking behavior for NSSI (Baetens et al., 2020), thus suggesting that effective school-based prevention programs need to include NSSI-specific psychoeducation. Overall, the literature documents the efficacy of cognitivebehavioral approaches in treating adolescent difficulties to manage negative emotions and distress in school contexts (Werner-seidler et al., 2017), with limited examples also in Italy (Ruini et al., 2009). A promising school-based approach is the DBT STEPS-A (Mazza et al., 2016), a universal social-emotional learning curriculum derived from the dialectical behavioral therapy (DBT) skills training component. DBT is an empirically supported psychological treatment for adults and adolescents with problems related to emotion dysregulation. It has shown relevant potential in alleviating the symptoms amongst adolescents who engage in NSSI (Mehlum et al., 2014). Furthermore, the skills taught in DBT have been found to be useful with a wide range of clinical and non-clinical populations (Mazza et al., 2016). The main goal of DBT STEPS-A is to help youth to develop effective strategies to regulate emotions, solve problems, make decisions, and improve their social relationships, including those with peers and teachers. However, there are only two evaluations of this program in educational settings, and neither included NSSI measures as an outcome (Rizvi \& Steffel, 2014; Zapolski \& Smith, 2017). Individuallevel clinical interventions may also play an important role in addressing NSSI, especially when the risk assessment indicates high risk levels. However, it is important to note that school response from a clinical perspective to NSSI still represents a serious concern due to the lack of appropriate guidelines and school policies to address NSSI, which may leave school mental health staff feeling unsupported (Kelada et al., 2017; Singer et al., 2019). Going beyond these objective difficulties, effective approaches could be those that encourage youth engaging in NSSI due to homophobic victimization to be open with their identities and feel free to actively explore identity alternatives. For instance, there is some evidence emphasizing self-compassion as a beneficial self-attitude that protects against harmful consequences associated with bullying victimization (Hatchel et al., 2019), including NSSI (Jiang et al., 2016). Thus, the implementation of school programs and services supporting healthy identity development may demonstrate to be beneficial for youth who struggle with homophobic victimization.

Supplementary Information The online version contains supplementary material available at https://doi.org/10.1007/s12310-021-09434-w. 
Funding Open access funding provided by Università degli Studi di Napoli Federico II within the CRUI-CARE Agreement. The authors received no specific funding for this work.

\section{Declarations}

Conflict of interest The authors declare that they have no conflict of interest.

Ethical approval All procedures performed in this study involving human participants were in accordance with the ethical standards of the institutional and national research committee and with the 1964 Helsinki declaration and its later amendments or comparable ethical standards.

Consent to participate Written informed consent was obtained from the parents. Informed assent was obtained from all adolescent participants included in the study.

Open Access This article is licensed under a Creative Commons Attribution 4.0 International License, which permits use, sharing, adaptation, distribution and reproduction in any medium or format, as long as you give appropriate credit to the original author(s) and the source, provide a link to the Creative Commons licence, and indicate if changes were made. The images or other third party material in this article are included in the article's Creative Commons licence, unless indicated otherwise in a credit line to the material. If material is not included in the article's Creative Commons licence and your intended use is not permitted by statutory regulation or exceeds the permitted use, you will need to obtain permission directly from the copyright holder. To view a copy of this licence, visit http://creativecommons.org/licenses/by/4.0/.

\section{References}

Aiken, L. S., West, S. G., Luhmann, M., Baraldi, A., \& Coxe, S. J. (2012). Estimating and graphing interactions. In H. Cooper, P. M. Camic, D. L. Long, A. T. Panter, D. Rindskopf, \& K. J. Sher (Eds.), APA handbook of research methods in psychology, Vol 3. data analysis and research publication (pp. 101-129). American Psychological Association Press. https://doi.org/10.1037/13621 $-005$

Bacchini, D., Esposito, C., Affuso, G., \& Amodeo, A. L. (2020). The impact of personal values, gender stereotypes, and school climate on homophobic bullying: a multilevel analysis. Sexuality Research and Social Policy. https://doi.org/10.1007/s13178-02000484-4

Baetens, I., Decruy, C., Vatandoost, S., Vanderhaegen, B., \& Kiekens, G. (2020). School-Based Prevention Targeting Non-Suicidal Self-injury. A Pilot Study, 11(May), 1-11. https://doi. org/10.3389/fpsyt.2020.00437

Barzilay, S., BrunsteinKlomek, A., Apter, A., Carli, V., Wasserman, C., Hadlaczky, G., Hoven, C. W., Sarchiapone, M., Balazs, J., Kereszteny, A., Brunner, R., Kaess, M., Bobes, J., Saiz, P., Cosman, D., Haring, C., Banzer, R., Corcoran, P., Kahn, J. P., ... Wasserman, D. (2017). Bullying victimization and suicide ideation and behavior among adolescents in Europe: a 10-country study. Journal of Adolescent Health, 61(2), 179-186. https://doi. org/10.1016/j.jadohealth.2017.02.002

Batejan, K. L., Jarvi, S. M., \& Swenson, L. P. (2015). Sexual orientation and non-suicidal self-injury: a meta-analytic review.
Archives of Suicide Research, 19(2), 131-150. https://doi. org/10.1080/13811118.2014.957450

Bauer, N. S., Lozano, P., \& Rivara, F. P. (2007). The effectiveness of the olweus bullying prevention program in public middle schools: a controlled trial. Journal of Adolescent Health, 40(3), 266-274. https://doi.org/10.1016/j.jadohealth.2006.10.005

Birkett, M., Espelage, D. L., \& Koenig, B. (2009). LGB and questioning students in schools: The moderating effects of homophobic bullying and school climate on negative outcomes. Journal of Youth and Adolescence, 38(7), 989-1000. https://doi. org/10.1007/s10964-008-9389-1

Bradlow, J., Bartram, F., Guasp, A., \& Jadva, V. (2017). School report. The experiences of lesbian, gay, bi and trans young people in Britain's schools in 2017. https://www.stonewall.org.uk/schoo 1-report-2017

Bradshaw, C. P., \& Johnson, R. M. (2011). The social context of bullying and peer victimization: an introduction to the special issue. Journal of School Violence, 10(2), 107-114. https://doi. org/10.1080/15388220.2011.557145

Breen, A. V., Lewis, S. P., \& Sutherland, O. (2013). Brief report: nonsuicidal self-injury in the context of self and identity development. Journal of Adult Development, 20(1), 57-62. https://doi. org/10.1007/s10804-013-9156-8

Brunstein Klomek, A., Snir, A., Apter, A., Carli, V., Wasserman, C., Hadlaczky, G., Hoven, C. W., Sarchiapone, M., Balazs, J., Bobes, J., Brunner, R., Corcoran, P., Cosman, D., Haring, C., Kahn, J. P., Kaess, M., Postuvan, V., Sisask, M., Tubiana, A., ... Wasserman, D. (2016). Association between victimization by bullying and direct self injurious behavior among adolescence in Europe: a ten-country study. European Child and Adolescent Psychiatry, 25(11), 1183-1193.https://doi.org/10.1007/s00787-016-0840-7

Busby, D. R., Horwitz, A. G., Zheng, K., Eisenberg, D., Harper, G. W., Albucher, R. C., Roberts, L. W., Coryell, W., Pistorello, J., \& King, C. A. (2020). Suicide risk among gender and sexual minority college students: The roles of victimization, discrimination, connectedness, and identity affirmation. Journal of Psychiatric Research, 121, 182-188. https://doi.org/10.1016/j.jpsychires 2019.11.013

Butler, J. (2011). Gender Trouble. Feminism and the Subversion of Identity. Routledge. https://doi.org/10.4324/9780203824979

Cipriano, A., Cella, S., \& Cotrufo, P. (2017). Nonsuicidal self-injury: a systematic review. Frontiers in Psychology. https://doi. org/10.3389/fpsyg.2017.01946

Claes, L., Luyckx, K., Baetens, I., Van de Ven, M., \& Witteman, C. (2015). Bullying and victimization, depressive mood, and non-suicidal self-injury in adolescents: the moderating role of parental support. Journal of Child and Family Studies, 24(11), 3363-3371. https://doi.org/10.1007/s10826-015-0138-2

Cobb, S. (1976). Social support as a moderator of life stress. Psychosomatic Medicine, 38(5), 300-314. https://doi.org/10.1097/00006 842-197609000-00003

Cohen, S. (2004). Social relationships and health. American Psychologist, 59(8), 676-684. https://doi. org/10.1037/0003-066X.59.8.676

Cohen, S., \& Wills, T. A. (1985). Stress, social support, and the buffering hypothesis. Psychological Bulletin, 98(2), 310-357. https:// doi.org/10.1037/0033-2909.98.2.310

D’Augelli, A. R., Pilkington, N. W., \& Hershberger, S. L. (2002). Incidence and mental health impact of sexual orientation victimization of lesbian, gay, and bisexual youths in high school. School Psychology Quarterly, 17(2), 148-167. https://doi.org/10.1521/ scpq.17.2.148.20854

Denny, S., Lucassen, M. F. G., Stuart, J., Fleming, T., Bullen, P., Peiris-John, R., Rossen, F. V., \& Utter, J. (2016). The association between supportive high school environments and depressive symptoms and suicidality among sexual minority students. 
Journal of Clinical Child \& Adolescent Psychology, 45(3), 248261. https://doi.org/10.1080/15374416.2014.958842

Diaz, E. M., Kosciw, J. G., \& Greytak, E. A. (2010). School connectedness for lesbian, gay, bisexual, and transgender Youth: In-school victimization and institutional supports. Prevention Researcher, 17(3), 15-17.

Discrimination in the European Union. Special Eurobarometer 493. (2019). https://ec.europa.eu/commfrontoffice/publicopinion/

Espelage, D. L., Aragon, S. R., Birkett, M., \& Koenig, B. W. (2008). Homophobic teasing, psychological outcomes, and sexual orientation among high school students: What influence do parents and schools have? School Psychology Review, 37(2), 202-216.

Espelage, D. L., Valido, A., Hatchel, T., Ingram, K. M., Huang, Y., \& Torgal, C. (2019). A literature review of protective factors associated with homophobic bullying and its consequences among children and adolescents. Aggression and Violent Behavior, 45, 98-110. https://doi.org/10.1016/j.avb.2018.07.003

Esposito, C., Bacchini, D., \& Affuso, G. (2019). Adolescent nonsuicidal self-injury and its relationships with school bullying and peer rejection. Psychiatry Research, 274, 1-6. https://doi. org/10.1016/j.psychres.2019.02.018

Fedewa, A. L., \& Ahn, S. (2011). New developments in the field: The effects of bullying and peer victimization on sexual-minority and heterosexual youths: A quantitative meta-analysis of the literature. Journal of GLBT Family Studies, 7(4), 398-418. https://doi.org/10.1080/1550428X.2011.592968

Garnett, B. R., Masyn, K. E., Austin, S. B., Miller, M., Williams, D. R., \& Viswanath, K. (2014). The intersectionality of discrimination attributes and bullying among youth: An applied latent class analysis. Journal of Youth and Adolescence, 43(8), 1225-1239. https://doi.org/10.1007/s10964-013-0073-8

Giletta, M., Scholte, R. H. J., Engels, R. C. M. E., Ciairano, S., \& Prinstein, M. J. (2012). Adolescent non-suicidal selfinjury: a cross-national study of community samples from Italy, the Netherlands and the United States. Psychiatry Research, 197(1-2), 66-72. https://doi.org/10.1016/j.psych res.2012.02.009

Gini, G., Pozzoli, T., Lenzi, M., \& Vieno, A. (2014). Bullying victimization at school and headache: a meta-analysis of observational studies. Headache: The Journal of Head and Face Pain, 54(6), 976-986. https://doi.org/10.1111/head.12344

Gonzalez-blanks, A., Bridgewater, J. M., Yates, T. M., Gonzalezblanks, A., Bridgewater, J. M., \& Yates, T. M. (2020). Statistical approaches for highly skewed data : evaluating relations between maltreatment and statistical approaches for highly skewed data : evaluating relations between maltreatment and young adults, non-suicidal self-injury. Journal of Clinical Child \& Adolescent Psychology, 49(2), 147-161. https://doi.org/10.1080/15374 416.2020.1724543

Haas, A. P., Eliason, M., Mays, V. M., Mathy, R. M., Cochran, S. D., D’Augelli, A. R., Silverman, M. M., Fisher, P. W., Hughes, T., Rosario, M., Russell, S. T., Malley, E., Reed, J., Litts, D. A., Haller, E., Sell, R. L., Remafedi, G., Bradford, J., Beautrais, A. L., ... Clayton, P. J. (2010). Suicide and Suicide Risk in Lesbian, Gay, Bisexual, and Transgender Populations: Review and Recommendations. Journal of Homosexuality, 58(1), 10-51. https://doi.org/10.1080/00918369.2011.53403810(1080/00918 369),pp.534038,2011

Hatchel, T., Merrin, G. J., \& Espelage, D. (2019). Peer victimization and suicidality among LGBTQ youth: the roles of school belonging, self-compassion, and parental support. Journal of LGBT Youth, 16(2), 134-156. https://doi.org/10.1080/19361 653.2018.1543036

Hatzenbuehler, M. L. (2009). Psychological Mediation Framework. Psychological Bulletin, 135(5), 707-730. https://doi.org/10.1037/ a0016441.How
Hershberger, S. L., \& D’Augelli, A. R. (1995). The impact of victimization on the mental health and suicidality of lesbian, gay, and bisexual youths. Developmental Psychology, 31(1), 65-74. https ://doi.org/10.1037/0012-1649.31.1.65

Holt, M. K., Vivolo-Kantor, A. M., Polanin, J. R., Holland, K. M., DeGue, S., Matjasko, J. L., Wolfe, M., \& Reid, G. (2015). Bullying and suicidal ideation and behaviors: a meta-analysis. Pediatrics, 135(2), e496-e509. https://doi.org/10.1542/peds.2014-1864

Hong, J. S., \& Garbarino, J. (2012). Risk and protective factors for homophobic bullying in schools: an application of the socialecological framework. Educational Psychology Review, 24(2), 271-285. https://doi.org/10.1007/s10648-012-9194-y

Ioverno, S., Nardelli, N., Baiocco, R., Orfano, I., \& Lingiardi, V. (2016). Homophobia, Schooling, and the Italian Context. In Sexual Orientation, Gender Identity, and Schooling (pp. 354-374). Oxford University Press. doi: https://doi.org/10.1093/med:psych /9780199387656.003.0020

Istituto Nazionale di Statistica (ISTAT). (2016). Rapporto Bes 2016: il benessere equo e sostenibile in Italia. https://www.istat.it/it/files //2016/12/BES-2016.pdf

Jiang, Y., You, J., Hou, Y., Du, C., Lin, M.-P., Zheng, X., \& Ma, C. (2016). Buffering the effects of peer victimization on adolescent non-suicidal self-injury: The role of self-compassion and family cohesion. Journal of Adolescence, 53, 107-115. https://doi. org/10.1016/j.adolescence.2016.09.005

Johnson, D. W., Johnson, R. T., Buckman, L. A., \& Richards, P. S. (1985). The effect of prolonged implementation of cooperative learning on social support within the classroom. The Journal of Psychology, 119(5), 405-411. https://doi.org/10.1080/00223 980.1985.10542911

Kelada, L., Hasking, P., \& Melvin, G. A. (2017). School response to self-injury: Concerns of mental health staff and parents. School Psychology Quarterly, 32(2), 173-187. https://doi.org/10.1037/ spq0000194

Kidger, J., Heron, J., Leon, D. A., Tilling, K., Lewis, G., \& Gunnell, D. (2015). Self-reported school experience as a predictor of self-harm during adolescence: A prospective cohort study in the South West of England (ALSPAC). Journal of Affective Disorders, 173, 163-169. https://doi.org/10.1016/j.jad.2014.11.003

Klemera, E., Brooks, F. M., Chester, K. L., Magnusson, J., \& Spencer, N. (2017). Self-harm in adolescence: protective health assets in the family, school and community. International Journal of Public Health, 62(6), 631-638. https://doi.org/10.1007/s0003 8-016-0900-2

Klonsky, E. D. (2007). The functions of deliberate self-injury: A review of the evidence. Clinical Psychology Review, 27(2), 226-239. https://doi.org/10.1016/j.cpr.2006.08.002

Kosciw, J. G., Greytak, E. A., Zongrone, M. P. ., Clark, C. M., \& Truong, N. L. (2018). The 2017 National School Climate Survey: The Experiences of Lesbian, Gay, Bisexual, Transgender, and Queer Youth in Our Nation's Schools. In Gay, Lesbian and Straight Education Network (GLSEN). https://www.glsen.org/ research/2017-national-school-climate-survey-0

Lakey, B., \& Cohen, S. (2000). Social Support Theory and Measurement. In Social Support Measurement and Intervention (pp. 29-52). Oxford University Press. doi: https://doi.org/10.1093/ med:psych/9780195126709.003.0002

Lambert, D. (1992). Zero-inflated poisson regression, with an application to defects in manufacturing. Technometrics, 34(1), 1-14. https://doi.org/10.2307/1269547

Limber, S. P., Olweus, D., Wang, W., Masiello, M., \& Breivik, K. (2018). Evaluation of the olweus bullying prevention program: a large scale study of U.S. students in grades 3-11. Journal of School Psychology, 69, 56-72. https://doi.org/10.1016/j. jsp.2018.04.004 
Liu, R. T., \& Mustanski, B. (2012). Suicidal ideation and self-harm in lesbian, gay, bisexual, and transgender youth. American Journal of Preventive Medicine, 42(3), 221-228. https://doi. org/10.1016/j.amepre.2011.10.023

Luthar, S. S., Cicchetti, D., \& Becker, B. (2000). The construct of resilience: A critical evaluation and guidelines for future work. Child Development. https://doi.org/10.1111/1467-8624.00164

Madjar, N., Ben Shabat, S., Elia, R., Fellner, N., Rehavi, M., Rubin, S. E., Segal, N., \& Shoval, G. (2017). Non-suicidal self-injury within the school context: Multilevel analysis of teachers' support and peer climate. European Psychiatry, 41, 95-101. https ://doi.org/10.1016/j.eurpsy.2016.11.003

Marshal, M. P., Dietz, L. J., Friedman, M. S., Stall, R., Smith, H. A., McGinley, J., Thoma, B. C., Murray, P. J., D’Augelli, A. R., \& Brent, D. A. (2011). Suicidality and depression disparities between sexual minority and heterosexual youth: a meta-analytic review. Journal of Adolescent Health, 49(2), 115-123. https:// doi.org/10.1016/j.jadohealth.2011.02.005

Mazza, J. J., Dexter-Mazza, E. T., Miller, A. L., Rathus, J. H., Murphy, H. E., \& Linehan, M. M. (2016). DBT® skills in schools: Skills training for emotional problem solving for adolescents (DBT STEPS-A). Guilford Press.

Mehlum, L., Tørmoen, A. J., Ramberg, M., Haga, E., Diep, L. M., Laberg, S., Larsson, B. S., Stanley, B. H., Miller, A. L., Sund, A. M., \& Grøholt, B. (2014). Dialectical behavior therapy for adolescents with repeated suicidal and self-harming behavior: a randomized trial. Journal of the American Academy of Child \& Adolescent Psychiatry, 53(10), 1082-1091. https://doi. org/10.1016/j.jaac.2014.07.003

Meyer, E. J. (2008). Gendered harassment in secondary schools: understanding teachers' (non) interventions. Gender and Education, 20(6), 555-570. https://doi.org/10.1080/09540250802213115

Meyer, I. H. (2003). Prejudice, social stress, and mental health in lesbian, gay, and bisexual populations: Conceptual issues and research evidence. Psychological Bulletin, 129(5), 674-697. https://doi.org/10.1037/0033-2909.129.5.674

Moore, S. E., Norman, R. E., Suetani, S., Thomas, H. J., Sly, P. D., \& Scott, J. G. (2017). Consequences of bullying victimization in childhood and adolescence: A systematic review and metaanalysis. World Journal of Psychiatry, 7(1), 60. https://doi. org/10.5498/wjp.v7.i1.60

Moran, P., Coffey, C., Romaniuk, H., Olsson, C., Borschmann, R., Carlin, J. B., \& Patton, G. C. (2012). The natural history of self-harm from adolescence to young adulthood: A population-based cohort study. The Lancet, 379(9812), 236-243. https://doi.org/10.1016/ S0140-6736(11)61141-0

Muehlenkamp, J. J., Brausch, A., Quigley, K., \& Whitlock, J. (2013). Interpersonal features and functions of nonsuicidal self-injury. Suicide and Life-Threatening Behavior, 43, 67-80. https://doi. org/10.1111/j.1943-278X.2012.00128.X

Muehlenkamp, J. J., Hilt, L. M., Ehlinger, P. P., \& McMillan, T. (2015). Nonsuicidal self-injury in sexual minority college students: a test of theoretical integration. Child and Adolescent Psychiatry and Mental Health, 9(1), 16. https://doi.org/10.1186/s1303 4-015-0050-y

Mulvey, K. L., Hoffman, A. J., Gönültaş, S., Hope, E. C., \& Cooper, S. M. (2018). Understanding experiences with bullying and bias-based bullying: What matters and for whom? Psychology of Violence, 8(6), 702-711. https://doi.org/10.1037/vio0000206

Muthén, L. K., \& Muthén, B. O. (2017). Mplus User's Guide (8th ed.). Muthén \& Muthén. https://doi.org/10.111 1/j.1600-0447.2011.01711.x

Nock, M. K. (2009). Why do people hurt themselves? Current Directions in Psychological Science, 18(2), 78-83. https://doi.org/10 .1111/j.1467-8721.2009.01613.x
Olweus, D. (1996). The Revised Olweus Bully/Victim Questionnaire. University of Bergen.

Olweus, D. (2010). Understanding and researching bullying: Some critical issues. In S. R. Jimerson, S. M. Swearer, \& D. L. Espelage (Eds.), Handbook of Bullying in Schools: An international perspective (pp. 9-34). Routledge.

Olweus, D., \& Limber, S. P. (2010). Bullying in school: Evaluation and dissemination of the Olweus bullying prevention program. American Journal of Orthopsychiatry, 80(1), 124-134. https:// doi.org/10.1111/j.1939-0025.2010.01015.x

Passani, A., \& Debicki, M. (2016). Students opinions and attitudes toward LGBT persons and rights: Results of a transnational European project. Journal of LGBT Youth, 13(1-2), 67-88. https ://doi.org/10.1080/19361653.2015.1087927

Plener, P. L., Schumacher, T. S., Munz, L. M., \& Groschwitz, R. C. (2015). The longitudinal course of non-suicidal self-injury and deliberate self-harm: a systematic review of the literature. Borderline Personality Disorder and Emotion Dysregulation, 2(1), 2. https://doi.org/10.1186/s40479-014-0024-3

Pontes, N. M. H., Ayres, C. G., Lewandowski, C., \& Pontes, M. C. F. (2018). Trends in bullying victimization by gender among U.S. high school students. Research in Nursing and Health, 41(3), 243-251. https://doi.org/10.1002/nur.21868

Poteat, V. P., DiGiovanni, C. D., \& Scheer, J. R. (2013). Predicting homophobic behavior among heterosexual youth: domain general and sexual orientation-specific factors at the individual and contextual level. Journal of Youth and Adolescence, 42(3), 351-362. https://doi.org/10.1007/s10964-012-9813-4

Poteat, V. P., \& Espelage, D. L. (2007). Predicting psychosocial consequences of homophobic victimization in middle school students. The Journal of Early Adolescence, 27(2), 175-191. https://doi.org/10.1177/0272431606294839

Poteat, V. P., Mereish, E. H., DiGiovanni, C. D., \& Koenig, B. W. (2011). The effects of general and homophobic victimization on adolescents' psychosocial and educational concerns: the importance of intersecting identities and parent support. Journal of Counseling Psychology, 58(4), 597-609. https:// doi.org/10.1037/a0025095

Poteat, V. P., Scheer, J. R., DiGiovanni, C. D., \& Mereish, E. H. (2014). Short-term prospective effects of homophobic victimization on the mental health of heterosexual adolescents. Journal of Youth and Adolescence, 43(8), 1240-1251. https:// doi.org/10.1007/s10964-013-0078-3

Prati, G., Pietrantoni, L., \& D'Augelli, A. R. (2011). Aspects of homophobia in italian high schools: students' attitudes and perceptions of school climate. Journal of Applied Social Psychology, 41(11), 2600-2620. https://doi.org/10.111 1/j.1559-1816.2011.00842.x

Price, M., Hill, N. E., Liang, B., \& Perella, J. (2019). Teacher relationships and adolescents experiencing identity-based victimization: what matters for whom among stigmatized adolescents. School Mental Health, 11(4), 790-806. https://doi.org/10.1007/s1231 0-019-09327-z

Prinstein, M. J., Nock, M. K., Simon, V., Aikins, J. W., Cheah, C. S. L., \& Spirito, A. (2008). Longitudinal trajectories and predictors of adolescent suicidal ideation and attempts following inpatient hospitalization. Journal of Consulting and Clinical Psychology, 76(1), 92-103. https://doi.org/10.1037/0022-006X.76.1.92

Reisner, S. L., Biello, K., Perry, N. S., Gamarel, K. E., \& Mimiaga, M. J. (2014). A compensatory model of risk and resilience applied to adolescent sexual orientation disparities in nonsuicidal selfinjury and suicide attempts. American Journal of Orthopsychiatry, 84(5), 545-556. https://doi.org/10.1037/ort0000008

Rinehart, S. J., Espelage, D. L., \& Bub, K. L. (2020). Longitudinal effects of gendered harassment perpetration and victimization on mental health outcomes in adolescence. Journal of Interpersonal 
Violence, 35(23-24), 5997-6016. https://doi.org/10.1177/08862 60517723746

Rizvi, S. L., \& Steffel, L. M. (2014). A pilot study of 2 brief forms of dialectical behavior therapy skills training for emotion dysregulation in college students. Journal of American College Health, 62(6), 434-439. https://doi.org/10.1080/07448481.2014.907298

Ross-Reed, D. E., Reno, J., Peñaloza, L., Green, D., \& FitzGerald, C. (2019). Family, school, and peer support are associated with rates of violence victimization and self-harm among gender minority and cisgender youth. Journal of Adolescent Health, 65(6), 776-783. https://doi.org/10.1016/j.jadohealth.2019.07.013

Ruini, C., Ottolini, F., Tomba, E., Belaise, C., Albieri, E., Visani, D., Offidani, E., Caffo, E., \& Fava, G. A. (2009). Journal of behavior therapy school intervention for promoting psychological wellbeing in adolescence. Journal of Behavior Therapy and Experimental Psychiatry, 40(4), 522-532. https://doi.org/10.1016/j. jbtep.2009.07.002

Russell, S. T., Sinclair, K. O., Poteat, P. V., \& Koenig, B. W. (2012). Adolescent harassment based on discriminatory bias. American Journal of Public Health, 102(3), 493-495. https://doi. org/10.2105/AJPH.2011.300430

Singer, J. B., Erbacher, T. A., \& Rosen, P. (2019). School-based suicide prevention: a framework for evidence-based practice. School Mental Health, 11(1), 54-71. https://doi.org/10.1007/s1231 0-018-9245-8

Slaatten, H., Anderssen, N., \& Hetland, J. (2015). Gay-related namecalling among Norwegian adolescents - harmful and harmless. Scandinavian Journal of Psychology, 56(6), 708-716. https:// doi.org/10.1111/sjop.12256

Smetana, J. G., Campione-Barr, N., \& Metzger, A. (2006). Adolescent development in interpersonal and societal contexts. Annual Review of Psychology, 57(1), 255-284. https://doi.org/10.1146/ annurev.psych.57.102904.190124

Swannell, S. V., Martin, G. E., Page, A., Hasking, P., \& St John, N. J. (2014). Prevalence of nonsuicidal self-injury in nonclinical samples: systematic review, meta-analysis and meta-regression. Suicide and Life-Threatening Behavior, 44(3), 273-303. https:// doi.org/10.1111/sltb. 12070

Swearer, S. M., Turner, R. K., Givens, J. E., \& Pollack, W. S. (2008). "You're so gay!": Do different forms of bullying matter for adolescent males? School Psychology Review, 37(2), 160-173.

Tager, D., \& Good, G. E. (2005). Italian and American masculinities: A comparison of masculine gender role norms. Psychology of Men \& Masculinity, 6(4), 264-274. https://doi. org/10.1037/1524-9220.6.4.264

Taliaferro, L. A., \& Muehlenkamp, J. J. (2017). Nonsuicidal self-injury and suicidality among sexual minority youth: risk factors and protective connectedness factors. Academic Pediatrics, 17(7), 715-722. https://doi.org/10.1016/j.acap.2016.11.002

Taylor, P. J., Jomar, K., Dhingra, K., Forrester, R., Shahmalak, U., \& Dickson, J. M. (2018). A meta-analysis of the prevalence of different functions of non-suicidal self-injury. Journal of Affective Disorders, 227, 759-769. https://doi.org/10.1016/j. jad.2017.11.073
Ttofi, M. M., Farrington, D. P., Lösel, F., \& Loeber, R. (2011). Do the victims of school bullies tend to become depressed later in life? A systematic review and meta-analysis of longitudinal studies. Journal of Aggression, Conflict and Peace Research, 3(2), 63-73. https://doi.org/10.1108/17596591111132873

Tucker, J. S., Ewing, B. A., Espelage, D. L., Green, H. D., de la Haye, K., \& Pollard, M. S. (2016). Longitudinal associations of homophobic name-calling victimization with psychological distress and alcohol use during adolescence. Journal of Adolescent Health, 59(1), 110-115. https://doi.org/10.1016/j.jadohealth .2016.03.018

Tucker, R. P., Wingate, L. R., \& O'Keefe, V. M. (2016). Historical loss thinking and symptoms of depression are influenced by ethnic experience in American Indian college students. Cultural Diversity and Ethnic Minority Psychology, 22(3), 350-358. https://doi. org/10.1037/cdp0000055

Valencia-Agudo, F., Burcher, G. C., Ezpeleta, L., \& Kramer, T. (2018). Nonsuicidal self-injury in community adolescents: A systematic review of prospective predictors, mediators and moderators. Journal of Adolescence, 65(2017), 25-38. https://doi. org/10.1016/j.adolescence.2018.02.012

van Geel, M., Goemans, A., \& Vedder, P. (2015). A meta-analysis on the relation between peer victimization and adolescent nonsuicidal self-injury. Psychiatry Research, 230(2), 364-368. https ://doi.org/10.1016/j.psychres.2015.09.017

Van Ryzin, M. J., Gravely, A. A., \& Roseth, C. J. (2009). Autonomy, belongingness, and engagement in school as contributors to adolescent psychological well-being. Journal of Youth and Adolescence, 38(1), 1-12. https://doi.org/10.1007/s10964-007-9257-4

Wang, C., Berry, B., \& Swearer, S. M. (2013). The critical role of school climate in effective bullying prevention. Theory into Practice, 52(4), 296-302. https://doi.org/10.1080/00405 841.2013.829735

Wasserman, D., Hoven, C. W., Wasserman, C., Wall, M., Eisenberg, R., Hadlaczky, G., Kelleher, I., Sarchiapone, M., Apter, A., Balazs, J., Bobes, J., Brunner, R., Corcoran, P., Cosman, D., Guillemin, F., Haring, C., Iosue, M., Kaess, M., Kahn, J.-P., ... Carli, V. (2015). School-based suicide prevention programmes: the SEYLE cluster-randomised, controlled trial. The Lancet, 385, 1536-1544.https://doi.org/10.1016/S0140-6736(14)61213-7

Werner-seidler, A., Perry, Y., Calear, A. L., Newby, J. M., \& Christensen, H. (2017). School-based depression and anxiety prevention programs for young people: A systematic review and meta-analysis. Clinical Psychology Review, 51, 30-47. https:// doi.org/10.1016/j.cpr.2016.10.005

Zapolski, T. C. B., \& Smith, G. T. (2017). pilot study: implementing a brief DBT skills program in schools to reduce health risk behaviors among early adolescents. The Journal of School Nursing, 33(3), 198-204. https://doi.org/10.1177/1059840516673188

Publisher's Note Springer Nature remains neutral with regard to jurisdictional claims in published maps and institutional affiliations. 